\title{
Design of an Interactive Playground Based on Traditional Children's Play
}

\author{
Daniel Tetteroo, Dennis Reidsma, Betsy van Dijk, and Anton Nijholt* \\ University of Twente, Department of Human Media Interaction \\ d.tetteroo@tue.nl, \{d.reidsma,e.m.a.g.vandijk,a.nijholt\}@utwente.nl
}

\begin{abstract}
This paper presents a novel method for interactive playground design, based on traditional children's play. This method combines the rich interaction possibilities of computer games with the physical and open-ended aspects of traditional children's games. The method is explored by the development of a prototype interactive playground, which has been implemented and evaluated over two iterations.
\end{abstract}

\section{Introduction}

Many governments pursue health care programs that promote a healthier youth. Still, children are unlikely to give up computer time in favor of outdoor play [8]. A solution may be the development of interactive playgrounds, consisting of "one or more interactive objects that use advanced technology to react to the interaction with children and actively encourage them to play" [17. They possess the rich interaction possibilities from computer games as well as the physical and social aspects of traditional outdoor play. Being an environment for play, rather than a game, they do not force strict rules upon the players, but provide possibilities for the children to define their own games. This form of "open-ended" play benefits children in many aspects of their development, such as social skills, problem solving, creativity, and a better understanding of the physical world [10 3 .

This paper presents a design method for developing interactive playgrounds, based on elements of traditional children's play, that should actively stimulate the development of children's physical, social and creative skills, without forcing game specific rules upon them, by combining the open-endedness of traditional outdoor play and the interactivity of modern computer games.

\section{Related Work}

Flash-Poles [17/2] are interactive poles, placed on a fixed position on a field. User tests indicated that they were successful in stimulating both cooperative and competitive physical play amongst children. The authors touch on a paradoxical issue in the design of installations for open-ended play. The interactive behaviour

* This research has been supported by the GATE project, funded by the Dutch Organization for Scientific Research (NWO) and the Dutch ICT Regie.

A. Camurri, C. Costa, and G. Volpe (Eds.): INTETAIN 2011, LNICST 78, pp. 129-138, 2012.

(C) Institute for Computer Sciences, Social Informatics and Telecommunications Engineering 2012 

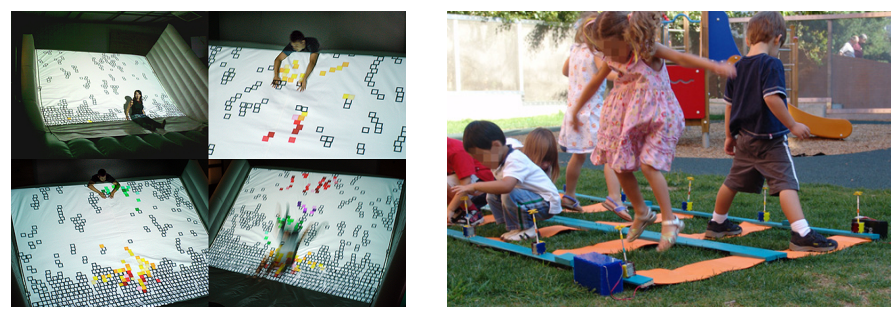

Fig. 1. The interactive slide (left) and the interactive pathway (right)

of the objects needs to be understandable for the children, but too many rules limit the possibilities for open-ended play. The Ledball [17] was developed to investigate the creation of new games by children using mobile play objects, but has not yet been evaluated.

The Playware playground tiles contain sensors, LED's and/or loudspeakers, plus processing capabilities to allow one to configure multiple tiles into different games [9]. Its evaluation focused on clear-defined games with fixed rules.

In the Interactive Slide (see Figure 1), a display is projected on a large, inflatable slide [15. The projection area is monitored by an IR camera, which allows for interactivity between the slide's users and the projection. Using an interaction driven design strategy, two games have been developed which aim at encouraging physical activity amongst children.

Space Explorers are a new category of animated playground props that allow children to explore the space around them in a playful manner [13. The prototype consists of a ball which moves around autonomously in a space, while interacting with the children present in the space. Children keep interacting with the ball as it moves around the space, such that they gradually discover the space around them. This shows there is potential for such playground props as mediating objects between a child and its play setting.

The Interactive Pathway (see Figure 1) is a rail-way like construction consisting of two wooden beams with a series of narrow pressure-sensitive mats connecting them [14]. On the wooden beams, "spinning tops" were placed, hand crafted by the children themselves. When a child steps on a mat, a motor causes one of the spinning tops to rotate. Evaluation showed that these quite simple interactions led to a wide range of open-ended play behaviour from the children.

\section{Traditional Children's Play}

Our goal was to design an intelligent, interactive playground, based on elements of traditional children's (outdoor) play. In this section we will discuss which dimensions of traditional play can be relevant in the design process. The project focuses on children in the age group between 8 and 12 years old. These children are able to perform advanced physical activities, define games rules and socially interact with each other [5, p.226] [12, p.251-252]. Furthermore, they are capable of actively taking part in evaluations involving group discussions and interviews. 


\subsection{Play, Games, and Playgrounds}

Huizinga, in the book Homo Ludens, argues that it is almost impossible to capture the properties of play in a single definition. Because the act of play does not necessarily have a goal and is by definition not bound to rules, almost any act could be considered an act of play [7. Games are a more formalized and strict form of play. "The game has a beginning, a middle, and a quantifiable outcome at the end. The game takes place in a precisely defined physical and temporal space of play. Either the children are playing Tic-Tac-Toe or they are not" [11, p. 25]. Open-ended play can evolve into a game over time, as players try to enforce certain play behaviour by defining rules and limitations.
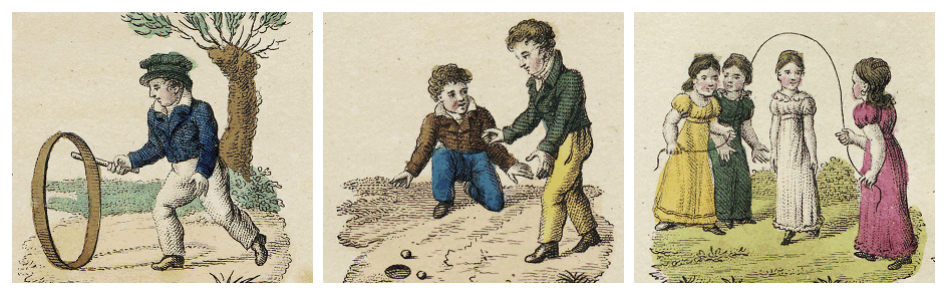

Fig. 2. Examples of traditional children's games: running the hoop, playing with marbles and the skip rope. 4, pgs. 33/3/36]

Children's games often require few attributes, consisting of little more than some simple toys, the players themselves and their creativity [16]. They often require physical activity and can be played with basic materials which can be carried along (hoop, ball, stick). Finally, the rules of such games are often few and simple, adaptable by the players themselves. Whether a stick is to be used for hitting, drawing or waving is up to the children inventing their game. The simple rules make the games very accessible and easy to understand for anyone eager to join a game, and make it easy to adapt a game by replacing, removing or adding a rule. It also makes it easy to convey these games from generation to generation. Sometimes, simple games - made-up by children themselves - can even have a higher appeal to them than more complex and predefined games [3].

Although play is potentially always and everywhere possible [20, most societies know the concept of playground as an environment specifically designated for play. The space may contain one or more playground artefacts. Traditional playground artefacts do not offer feedback and do not actively interact with the user. For example, a slide is often a rigid wooden structure which just 'sits' there in a playground. However, its presence within the playground allows for a number of ways to interact with it (climbing up the slide, sliding downwards, hiding beneath the slide), and children, when incorporating the artefact in their play, may assign any meaning to it when it fits their current play. 

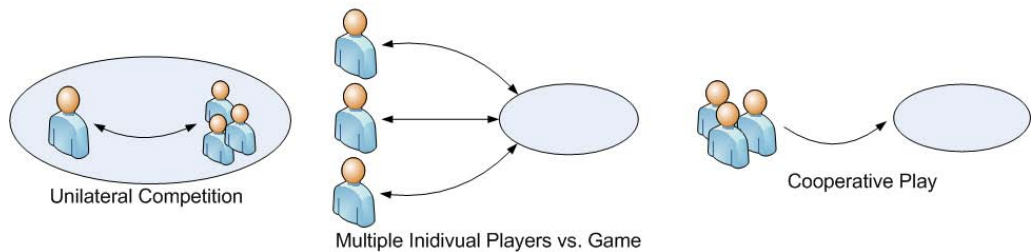

Fig. 3. A subset of the player interaction patterns from Fullerton et al. [6, p.46].

\subsection{A Taxonomy for Playground Play}

In order to design our interactive playground using elements of traditional children's play, we need a taxonomy to describe these elements in a structured way. For this, we draw from related work in interaction design, we introduce the idea of Gamespace in playgrounds, and finally elaborate our taxonomy based on an analysis of many types of traditional playground play.

Elements from Related Work in Interaction Design. Sturm et al. address five key issues for the successful design of an intelligent, interactive playground of open-ended play: social interaction, simplicity, challenge, goals and feedback 17. Soute et al. 16 discuss that one should address social interaction, fun, physical activity, and flexible and adaptable rules in order to combine the appeal of indoor digital games with the benefits of traditional outdoor play in Head Up Games. Fullerton et al. [6, p.46], finally, defined seven different player interaction patterns (see Figure 3). Social interaction between the players could be enhanced by facilitating competitive or cooperative play.

Gamespace. We introduce Gamespace as a one-dimensional measure defining to which degree an act of play, or a game, is related to the play-environment or playground in which it occurs. We define gamespace on a sliding scale on which three global levels can be defined (see Figure 4):

- Fully external: the playground is irrelevant to the game, except as the location where it takes place. For example, children throw a ball back and forth without looking at, or making use of what is in the playground.

- Partially contained: the game is not mainly dependent on the playground, but incorporates elements of the playground. For example, the children play cops and robbers, and use the climbing frame as the robbers' home base.

- Fully contained: the game takes place entirely within the playground. For example, the children are swinging or using the seesaw.

We aim to merge traditional children's play and modern computer gaming into an interactive playground. Ideally, a passer-by would see children playing together, and only with a closer look would discover that the playground is technologically enhanced. In a similar fashion, the children playing on the playground would incorporate elements of the interactive playground in their play, but would not let the digital enhancements overshadow their play. Ideally, the games played 


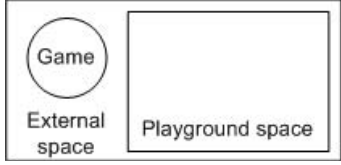

(a) Fully external

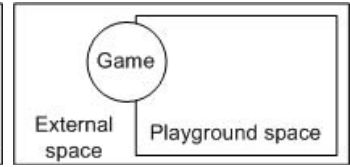

(b) Partially contained

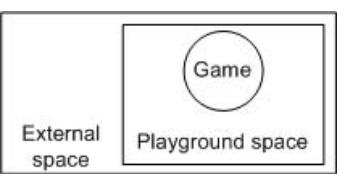

(c) Fully contained

Fig. 4. Gamespace levels

within the playground would be partially contained. It should be stimulated and facilitated by the playground, but not be fully dependent on it.

A Design Taxonomy for Playgrounds. Based on the key issues described above, we define our taxonomy in three layers (see Figure 51). The top level is made up of three highly abstract 'classes', that also define global goals for the playground: (1) Gamespace, (2) social interaction, and (3) physical activity. We want our interactive playground to encourage physical activity and social interaction, and we want the resulting children's play to be partially contained in the playground's gamespace. We argue that the other key issues can be handled by carefully planning the social and physical dimensions of a playground. For example, by providing possibilities for competition (which is a form of social interaction), both a challenge and a possible goal (being 'better' than other players) are created for the players. The bottom level of our taxonomy is made up of a set of single interaction patterns between children and the (enhanced) playground. An example of a single interaction is the playground responding to shouting children by changing the colour of the playground's surface. The distance between the interactions and the classes is very large, so it is very difficult to derive the one from the other without resorting to an intermediate level. To bridge the gap, we have analysed a large number of traditional outdoor children's games. By analysing these games along the aforementioned classes and by comparing and weighing their individual properties, we constructed a set of 20 dimensions. Some example dimensions are competition, collaboration and item possession. The list of dimensions can be found in Appendix A more extensive details on the dimensions can be found in [19].

\section{A Novel Approach to Interactive Playground Design}

Although a lot is known about key issues for interactive playgrounds through evaluation studies of various prototypes (cf. the sections above), a fully structured method leading from a playground concept to interactions for a working prototype is still lacking. This section aims to fill this gap by introducing a novel approach for interactive playground design that results in a tight integration of traditional children's play and modern computer gaming. This section introduces the four-stage design process In the next section we will describe a case study that we performed using this method. 


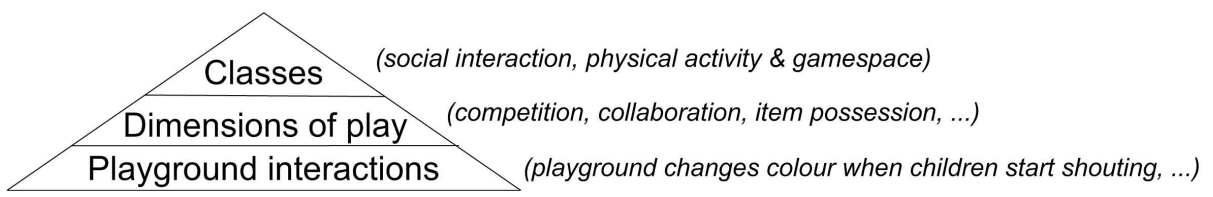

Fig. 5. Playground interaction design levels

Concept Generation. The method starts with Concept Generation. This phase aims to arrive at an overall 'story concept' that will drive the design, using the classes defined in the previous section as guidelines. First, a number of candidate 'story concepts' are described. Out of these, one concept is selected for further development, choosing on the basis of suitability for open-ended play: the concept must be concrete enough to be able to derive possible interactions from it, but it should not be so concrete as to block the children from evolving their own play in the playground. For example, a story concept might center on "make a playground that is like a giant complex machine with moving parts", or "make a playground inhabited by many creatures".

Interactions Generation. The story concept sketches the rough contours along which we can design the playground's interactions. The second phase is to develop single Interactions that children can have with the playground. For each of the 20 dimensions determined earlier, a single interaction possibility is designed. An interaction may be related to more than one dimension, but at least we make sure that every dimension is related to at least one interaction. For example, an interaction, related to dimension 16 (see appendix), might be "If you step on a spinning gear in the machine, it will start making a noise".

Systematic Variation on Interactions. The fourth step in the design process is one of Systematic Variation. In this phase, every interaction developed during the previous phase is analysed along all 20 dimensions. Wherever possible, a new interaction is derived by adding the dimension if it was not yet present in the interaction, or by inverting the role of the dimension, if it was. This phase adds yet more structure to the design and yields a vastly more extensive set of interactions, with a better coverage of the various dimensions, and therefore of the three abstract 'classes'.

Selection. The final step in the design process is the Selection of interactions which will be implemented. Because the previous phase will tend to create numerous contradicting and opposing interactions, selection is not a trivial task. Criteria to guide the selection process, besides practical reasons of feasibility, are: (1) Which dimensions are covered by the selected interaction methods? (2) Do the chosen interactions form a balanced system? If there are, for example, mechanics for introducing new (virtual) objects into the playground, there should be mechanics for reducing their amount as well, to avoid clutter. 


$\begin{array}{ll}\text { Initial situation: } & \text { Two or more players with a ball within the playground } \\ \text { Action performed: } & \text { Two players let their balls touch for a moment } \\ \text { System reaction IM2: } & \text { A new shape is created near both players } \\ \text { Rationale: } & \text { Introduces element of collaborative play } \\ \text { System reaction IM22: } & \text { Tails of both players switch owners } \\ \text { Rationale: } & \text { Competitive instead of collaborative play }\end{array}$

Fig. 6. IM22 is a variation on IM2; collaboration becomes competition

\section{Case Study}

Using the design approach summarized above, we developed an interactive playground and evaluated it in a user study with 19 children.

Concept Generation. The initial story concept was as follows:11):

"The playground space is initially empty. When a player enters the playground, (s)he gets surrounded by a simple unique shape in an arbitrary colour. The shape follows him/her wherever (s)he goes. When two players get in touching distance, a smaller 'offspring' shape is created, based on the players' shapes. The offspring get their own 'life' travelling around within the playground. Players are allowed to interact with the shapes through collecting, stealing, killing or moving offspring shapes. The shape ecosystem contains control mechanisms, such as a predator shape, to provide additional dynamics to the playground."

Interaction Generation and Systematic Variation. Systematic variation of the initial set of 20 interaction methods (one for each dimension) resulted in 32 additional interactions. Full details can be found in [19]; for reasons of space we only mention one example of variation (Fig. 6). In the original interaction, physical contact between two players triggers the 'birth' of a new shape. The variation shows a different system response: the players' tails switch owners, causing collaborative play to become competitive play.

Selection. Of the 52 interactions resulting from systematic variation, 13 were implemented in our playground. The playground interactions are centered around shapes that normally lead a life floating around the playground freely, but which can be captured by players who chase them. Captured shapes follow a player in a tail, but can also be stolen by other players that chase the tail for a while. Players can create new shapes by standing together, and destroy each others' shapes by running through another player's tail. Each player can, by shaking a ball (s)he carries, create a pool of poisonous venom that destroys other players' shapes. All of these actions influence a player's status, which is expressed by the size of a circle projected around them.

\footnotetext{
${ }^{1}$ cf. http://hmi.ewi.utwente.nl/showcase/anemone: emergent entertainment/
} 

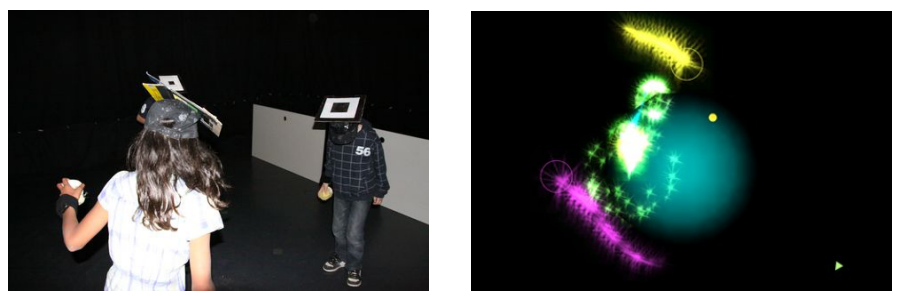

Fig. 7. The interactive playground

\section{$5.1 \quad$ Implementation}

The interactive playground was implemented in the SmartXP laboratory of the University of Twente, using top projection and an infrared camera over an area of $6 \times 6$ meters. The players' positions were tracked by the infrared camera, filming reflective markers mounted on the children's heads. Small foam balls were equipped with Sun SPOT sensors [18. The sensors allowed us to detect when a ball is shaken and by whom (because the players were wearing another Sun SPOT sensor around their wrist).

\subsection{Evaluation}

The playground was evaluated to test the relation between the children's play and the implemented interactions. Children were invited to play in the playground during 30 minute sessions in 2-4 person groups (see Figure 7). A modified version of the OPOS observation scheme [1] was used to record observations along the three classes defined in section 3.2 . We observed numerous games, such as throwing a ball and games of tag. Most games were strongly related to the children's presence in the playground. Examples are catch-the-shapes, scarethe-monster and switch tails. Most observed games were fully contained within the playground's gamespace; only a few were partially contained. This effect might be due to novelty of the playground, which incited children to focus on exploration of the playground's possibilities. Concerning (social interaction \& physical play), there are strong hints that the implemented interactions influenced children's play behaviour in the intended way. Concluding interviews with the children indicated that they were very fond of the interactive playground and were willing to give up computer gaming time to play in the playground.

\section{Conclusions and Recommendations}

This paper presented the design, implementation and evaluation of an interactive, intelligent playground. A novel design approach has been used in which the design of the interactive playground is based on elements of traditional children's games. Ideally, a passer-by would see children playing together on a playground and only with a closer look, (s)he would discover that the playground is 
technologically enhanced. In a similar fashion, the children playing on the playground should feel the same excitement they feel when playing computer games and only on second thought notice that they are participating in socio-physical play. A playground resulting from the approach should combine the merits of both traditional outdoor play and modern computer gaming.

An example playground was designed and implemented using the novel method, and was evaluated in a user study with 19 children. The children who participated in the evaluation showed great enthusiasm. Almost without exception, they were prepared to give up computer gaming time in exchange for spending time with the interactive playground. Considering the motivation of this project, this promises a hopeful future for interactive playgrounds. To further verify the validity of the proposed design method, both the current playground concept and alternative concepts should be tested in experiments focussing on long-term usage of the designed playground in a realistic setting.

\section{References}

1. Bakker, S., Markopoulos, P., de Kort, Y.: OPOS: an observation scheme for evaluating head-up play. In: NordiCHI 2008, pp. 33-42 (2008)

2. Bekker, M., van den Hoven, E., Peters, P., Hemmink, B.k.: Stimulating children's physical play through interactive games: two exploratory case studies. In: Proc. of IDC 2007, pp. 163-164. ACM, New York (2007)

3. Bekker, T., Sturm, J., Wesselink, R., Groenendaal, B., Eggen, B.: Interactive play objects and the effects of open-ended play on social interaction and fun. In: Proc. of ACE 2008, pp. 389-392. ACM, New York (2008)

4. Cornelisz, J.H.: Kinderspelen, in leerzame gedichtjes. Ten Brink en De Vries, Amsterdam (1837)

5. Del Alamo, M.R.: Design for Fun: Playgrounds. Links International (2004)

6. Fullerton, T., Swain, C., Hoffman, S.: Game design workshop: designing, prototyping, and playtesting games. Focal Press (2004)

7. Huizinga, J.: Homo ludens. Proeve eener bepaling van het spel-element der cultuur. H.D. Tjeenk Willink \& Zoon (1950)

8. Jansen, W., Mackenbach, J.P., van Zwanenburg, E.J., Brug, J.: Weight status, energy-balance behaviours and intentions in 9-12-year-old inner-city children. Journal of Human Nutrition and Dietetics 23(1), 85-96 (2010)

9. Lund, H.H., Klitbo, T., Jessen, C.: Playware technology for physically activating play. Artificial Life and Robotics 9(4), 165-174 (2005)

10. Rogers, Y., Price, S.: Extending and augmenting scientific enquiry through pervasive learning environments. Children, Youth and Env. 14(2), 67-83 (2004)

11. Salen, K., Zimmerman, E.: Rules of play: game design fundamentals (2003)

12. Schenk-Danzinger, L.: Entwicklungspsychologie. BV (1977)

13. Seitinger, S.: Animated props for responsive playspaces. Masters's thesis in Media Arts and Sciences, Massachusetts Institute of Technology (2006)

14. Seitinger, S., Sylvan, E., Zuckerman, O., Popovic, M., Zuckerman, O.: A new playground experience: going digital? In: CHI 2006, pp. 303-308 (2006)

15. Soler-Adillon, J., Ferrer, J., Parés, N.: A novel approach to interactive playgrounds: the interactive slide project. In: Proc. of IDC 2009, pp. 131-139. ACM, New York (2009) 
16. Soute, I., Markopoulos, P., Magielse, R.: Head up games: combining the best of both worlds by merging traditional and digital play. Pers. and Ubiquit. Comput. 14, 435-444 (2009)

17. Sturm, J., Bekker, T., Groenendaal, B., Wesselink, R., Eggen, B.: Key issues for the successful design of an intelligent, interactive playground. In: Proc. of IDC 2008, pp. 258-265. ACM, New York (2008)

18. Sun Microsystems Inc. Sun spot system: Turning vision into reality. Technical White Paper on Sun SPOTs (June 2005)

19. Tetteroo, D.: Design of an interactive playground based on traditional childrens play. Masters's thesis in Human Media Interaction, University of Twente (2010)

20. Wigley, M.: Constant's New Babylon: The Hyper-architecture of Desire (1998)

\section{A Game dimensions}

1. The dominant player interaction pattern [6] associated with the game.

2. Physical skills: the amount of physical activity involved in the game.

3. Social skills: the amount of social activity involved in the game.

4. Creative skills: the amount of creativity involved in the game.

5. Tactical skills: the extent to which tactics can be applied to the game.

6. Is finite?: whether the game is limited by some intrinsic rule or condition.

7. Has goal?: whether the game has a concrete and defined goal.

8. Is competitive?: whether competition plays a role in the game.

9. Single / multiplayer

10. Amount of space required

11. Whether chasing other players is a factor in the game.

12. Player's visibility is essential part of the game?

13. Whether the game contains a promotion / degradation mechanism.

14. Allows 'game over': whether a player can lose or not win the game.

15. Time limit: whether the game is strictly limited in time.

16. Sound: whether sound plays (or can play) a determining role in the game.

17. Physical contact between players required?

18. Requires extra (physical) items or resources

19. Shared / individual items: whether ownership of the item(s) is shared.

20. Item possession is a (sub)goal in itself? 